\title{
The immediate effect of different mandibular positions on muscle force in the upper and lower limb: A pilot study in asymptomatic subjects
}

\author{
Hans Isselée ${ }^{1}$, Anouk Asscherickx ${ }^{2}$, Bernard De Mot ${ }^{2}$, Wim Dankaerts ${ }^{1}$, Filip Staes ${ }^{1}$, Jan Deklerck ${ }^{1}$, Jan De Neve ${ }^{3}$ and Antoon De Laat ${ }^{4}$ \\ ${ }^{1}$ KU Leuven University of Leuven, Department of Rehabilitation Sciences, Faculty of Kinesiology and Rehabilitation Sciences, KU Leuven, Belgium \\ ${ }^{2}$ Training center for Dental Students of the KU Leuven, Sint-Jan Hospital, Bruges, Belgium \\ ${ }^{3}$ Division of Sports Medicine and Rehabilitation, Sint-Jan Hospital, Bruges, Belgium \\ ${ }^{4}$ KU Leuven University of Leuven, Department of Oral Health Sciences, Faculty of Medicine and Dentistry, Univ. Hospitals KU Leuven, Belgium
}

\begin{abstract}
It has been suggested that occlusal splints can improve muscle strength in athletes by affecting the mandibular position. However, research in this area is scarce and conflicting. This pilot study evaluated the upper and lower limb muscle force in three different mandibular positions and assessed the repeatability of these measurements. Twenty one healthy subjects (13 males - 8 females) aged 18-24 years were recruited among physiotherapy students based on strict criteria. Included subjects were free of any temporomandibular, oral or musculoskeletal disorders. For each subjects individually a hard wax bite of $2-4$ mm in maximal occlusion was made. Grip strength was measured using the Biometrics ${ }^{\circledR}$ dynamometer. Isometric muscle force of the quadriceps was measured using a BIODEX ${ }^{\circledR}$ dynamometer. Muscle force in shoulder abduction muscles was measured using a MicroFET ${ }^{\circledR}$ dynamometer. Three trials within each session, and in a random order, were done in each of three mandibular positions: 1) closed in maximal occlusion; 2) active mouth opening; 3) closed on wax bite in maximal occlusion. This procedure was repeated after a one week period. To control for confounding of mandibular position, within-session trials and test day, a linear mixed covariance model approach was used. No significant differences were found in muscle force between the three mandibular positions for any of the muscle groups tested ( $\mathrm{p}>0.05$ ). Good repeatability was demonstrated within one session and between two separate days. Findings indicate that in asymptomatic subjects, muscle force in the limbs was not influenced by altered mandibular position.
\end{abstract}

\section{Background}

During the past decades, it has been suggested that mandibular position or occlusal factors can affect other parts of the body such as body posture, muscle force or athletic performance [1-3].

However, until now, neither relevant clinical nor scientific evidence has been found for these suggested associations. Regarding the relation between orthopaedic and dental symptoms or findings, recent literature reviews reported that most publications failed to provide evidence for a cause-effect relationship [4-6]. Despite it has been demonstrated that occlusal interferences can have small influences on kinematic parameters related to mandibular position, it has not been shown that these can modify static and dynamic parameters of body posture significantly over time [7]. The relation between mandibular position and muscle force is controversial. The study of Smith (1978) was one of the first studies published on this topic. That study reported that an increase in vertical dimension of dental occlusion could increase muscle force of the shoulder abduction muscles in subjects with temporomandibular joint (TMJ) disorders. Other studies reported that an occlusal splint increased muscle force in shoulder adductor and abductor muscles [2] or back and lower limb muscles [8]. In addition, in sports literature, it has been suggested that wearing a mandibular orthopaedic repositioning appliance (MORA) can improve athletic performance such as vertical jumping and grip strength [9]. Moreover, it has been reported that wearing a mouthguard improved physical performance of the upper limbs [10] while other studies failed to show an effect $[11,12]$.
However, small vertical changes of the jaw could affect the motor recruitment of the masseter and the fine-motor skills of the masticatory system [13]. Studies using surface EMG reported that occlusal interferences could modify the contraction pattern of the masticatory muscles as well as muscles of other parts of the body [14,15]. However, the clinical significance for these biological and experimental findings has not been demonstrated [15].

A close integration of the jaw and neck motor systems has been described in animal and human studies demonstrating co-activation and reflex activities of jaw, neck and shoulder muscles [16,17]. Moreover, a recent fMRI analysis in healthy subjects showed that mandibular position and it's alternation by an occlusal splint can affect motor and somatosensory cortical activation and cerebellar networks [18]. Since the mandibular position is directly functionally related to the cervical region function, which has a significant effect on postural control mechanisms in general [19], it is interesting to further explore the clinical evidence of mandibular position on other parts of the body. A number of studies have demonstrated that voluntary teeth clenching

Correspondence to: Dr. H. Isselée, KU Leuven, Campus Brugge, Xaverianenstraat 10, B-8200 Sint Michiels, Belgium, E-mail: hans.isselee@faber.kuleuven.be

Key words: dental occlusion, occlusal splints, vertical dimension, quadriceps muscle, muscle skeletal, hand

Received: May 10, 2016; Accepted: June 09, 2016; Published: June 13, 2016 
facilitated the H-reflex in both the agonist and antagonist muscles of the lower limb [20,21], suggesting that sensory information arising from masticatory systems during clenching of the teeth strengthens the tonic muscles. Also, there appeared to be interactions between the masticatory activity and that of the muscles of the lower limb [22]. At present, some athletes wear occlusal splints or mouthguards during sports activity notwithstanding the lack of scientific evidence. Since the repeatability of potential effects between two separate days was not studied and only limited information is available with regard to the effect of mandibular position on muscle strength in the limbs, the aim of the present study was 1) to measure the possible effect of different vertical mandibular positions on muscle force in the limbs and 2) to evaluate the reproducibility of the measurements within 1 session and after a period of one week.

\section{Methods}

\section{Subjects}

Twenty-one healthy subjects, 13 males and 8 females were recruited among physiotherapy students. The mean age of the males was 19.6 years (range 18 to $28 \mathrm{yr}$ ). The mean age of the females was 19.2 years (range 18 to $20 \mathrm{yr}$ ). All subjects underwent a routine medical and standardized physical examination by a trained physician. Subjects were excluded if they presented 1) systematic diseases, 2) musculoskeletal disorders, 3) current treatment for orthopaedic conditions, 4) recent trauma to both upper and lower limb. According to the requirements of the physiotherapy program of the faculty, all subjects had a sufficient active and physical exercise level. Subjects also underwent a routine dental and TMD examination by a trained dentist. To be included, the subjects had to be subjectively and clinically free from TMD and not present with any intra-oral pathology or complaints based on the Research Diagnostic Criteria for TMD [23]. Subjects were furthermore excluded if they presented with a class II-III teeth relation, deep bite or cross bite. In all subjects who met the inclusion criteria, a hard wax bite of 2-4 mm thickness, taken in maximal occlusion, was individually made. All subjects were blinded for the hypothesis of the study but were well informed about the procedures and gave informed consent. The study was approved by the Ethical Committee of St. John's Hospital AZ Sint-Jan AV Bruges.

\section{Muscle test procedures}

Three trials were randomly scheduled in each of the following three mandibular positions: 1) mouth closed in maximal occlusion 2) maximal active mouth opening and 3) mouth closed on a wax bite in maximal occlusion. Subjects were thoroughly familiarized with all test procedures before the initial test. All tests were performed by the same examiner. Subjects were invited to participate in a re-test a week after the first test moment and twelve subjects were able to do.

\section{Concentric peak force handgrip test}

Functional maximal handgrip strength was measured in sitting position with the electronic Precision Dynamometer G200, (Biometrics ${ }^{\circ}$, Ltd, Newport UK) on the preferred arm [24]. The upper arm was held against the trunk, elbow in $90^{\circ}$ of flexion, forearm and wrist in neutral position. The examiner ensured that no external or internal rotation in the shoulder was present. Subjects were asked to maximally squeeze the dynamometer three times for three seconds, with a recovery time of 20 seconds between every successive measurement. This was performed in the three mandibular positions in a random order with a rest interval of one minute between the mandibular positions. Standardized verbal encouragement was given.

\section{Isometric peak force upper limb}

The isometric muscle force of the upper limb was measured using the eccentric break test method for the abductors of the shoulder [25]. This test starts as an isometric contraction but then the examiner gradually increases the force, trying to cause an eccentric contraction or a "break" in the subjects contraction. The device quantifies the breaking force necessary to depress the limb. This method provides a more recognizable threshold for maximum contraction than isometric testing. Objective values were obtained by using a Biometrics MicroFET $^{\varpi} 2$ hand held dynamometer (Biometrics Ltd, Newport, UK). The test was performed on the dominant side, defined as the preferred use for this performance, from a standardized position. All tests were done in a reclined position. The tested arm was in $45^{\circ}$ of shoulder abduction, elbow extended and elbow and wrist in supination. The MicroFET ${ }^{\circledast}$ hand held dynamometer was placed on the lateral epicondyl. During six seconds, standardized using a chronometer, the maximal force was built up. The examiner verbally encouraged all subjects in a standardized way. Three trials were randomly done in each of the three mandibular positions, with a 20-second rest interval between each trial and a one minute interval between every mandibular position. Subjects performed general warming up exercises for the shoulders before the test.

\section{Isometric peak torque of the $\mathbf{m}$. quadriceps}

The isometric maximum voluntary contraction (MVC) force of the quadriceps muscles was measured with the BIODEX ${ }^{\circledR}$ dynamometer System 4 Pro $^{\mathrm{TM}}$, (Biodex Medical Systems, New York) with the knee angle held at 60 degrees. The peak torque of the preferred leg was measured for six seconds. Two trials were randomly done in each of the three mandibular positions, with a one minute rest interval between each trial and a two minute interval between every mandibular position. As warming-up before the test, subjects had to cycle at 50 Watt for 10 minutes and jumped one minute.

\section{Statistical analysis}

To control for confounding of mandibular position, withinsession trials and test day, a linear mixed covariance model approach was used. The mean, SD and coefficient of variation was calculated for the repeated measurements for each mandibular position for both test days. In the mixed model, the within-session trials, mandibular position and test day were the fixed effects. Classic ANOVA demands that all measurements be independent. The present study design of repeated measures, however, could result in clusters of data. To take this clustering into account, the mixed model includes a correction for the correlation between measurements within the same individual. The level of significance was set at $\mathrm{p}<0.05$.

\section{Results}

The mean, SD and coefficient of variation of the handgrip peak force in different mandibular positions are presented in Table 1. On the first test day, 21 subjects performed three consecutive trials in each mandibular position within one session resulting in 63 repeated measurements $(n=63)$ for the handgrip and shoulder muscles. On the second test day 36 repeated measurements for handgrip and shoulder muscles were performed by 12 subjects. Table 2 shows the p-values for the confounding factors within-session trials, mandibular position and day on the handgrip, shoulder and quadriceps muscle. As showed in table 2 the mandibular position had no significant influence on the handgrip peak force $(\mathrm{p}=.837)$ and no significant influence on the peak force of the shoulder abduction muscles $(\mathrm{p}=.929)$. Also, hand grip 
Table 1. Descriptive values and coëfficiënt of variation for handgrip muscle strength in $\mathrm{kgs}$ in 3 different mandibular positions on two separate test days. $n=$ number of measurements.

\begin{tabular}{|c|c|c|c|c|c|}
\hline \multicolumn{2}{|c|}{ mandibular position } & n & mean & SD & VAR \\
\hline closed & Day 1 & 63 & 38.1 & 11.5 & 30.3 \\
\hline & Day 2 & 36 & 36.4 & 8.5 & 23.5 \\
\hline open & Day 1 & 63 & 37.7 & 11.8 & 31.3 \\
\hline & Day 2 & 36 & 36.2 & 8.9 & 24.7 \\
\hline closed +bite & Day 1 & 63 & 38.2 & 12.3 & 32.2 \\
\hline & Day 2 & 36 & 37.7 & 9.9 & 26.3 \\
\hline Total & Day 1 & 189 & 38.0 & 11.8 & 31.1 \\
\hline & Day 2 & 108 & 36.8 & 9.11 & 24.8 \\
\hline
\end{tabular}

Table 2. p-values presented for handgrip strength as dependent variable. The table shows (a) the effect of within session trials, mandibular position and day on the handgrip strength and (b) the p-values for the interactions between the fixed factors.

\begin{tabular}{|l|c|}
\hline \multicolumn{1}{|c|}{ Factors } & P-values \\
\hline \multicolumn{2}{|c|}{ (a) Effect of co-factors on handgrip } \\
\hline within session trials & 0.520 \\
\hline mandibular position & 0.837 \\
\hline day & 0.361 \\
\hline \multicolumn{2}{|c|}{ (b) Effect of interactions between fixed factors } \\
\hline trial $v s$. mand pos & 0.999 \\
\hline trial $v s$. day & 0.957 \\
\hline mand pos $v s$. dag & 0.924 \\
\hline trial vs mand pos $v s$. day & 1.000 \\
\hline
\end{tabular}

Table 3. Descriptive values and coëfficiënt of variation for quadriceps muscle strength in $\mathrm{Nm}$ in 3 different mandibular positions on two separate test days. $\mathrm{n}=$ number of measurements.

\begin{tabular}{|c|c|c|c|c|c|}
\hline \multicolumn{2}{|c|}{ mandibular position } & n & mean & SD & VAR \\
\hline closed & Day 1 & 21 & 176.8 & 57.3 & 32.4 \\
\hline & Day 2 & 12 & 173.2 & 45.0 & 26.0 \\
\hline open & Day 1 & 21 & 174.5 & 52.4 & 30.3 \\
\hline & Day 2 & 12 & 170.7 & 46.4 & 27.2 \\
\hline closed +bite & Day 1 & 21 & 178.7 & 56.0 & 31.4 \\
\hline & Day 2 & 12 & 168.5 & 42.0 & 24.9 \\
\hline Total & Day 1 & 63 & 176.6 & 54.4 & 30.8 \\
\hline & Day 2 & 36 & 170.8 & 43.2 & 25.3 \\
\hline
\end{tabular}

peak force was not affected by the repeated measures $(\mathrm{p}=.52)$ showing good repeatability within one session. The factor day of measurement had no significant influence on the hand grip peak force $(\mathrm{p}=.361)$ demonstrating good repeatability between two separate days. The peak force of the shoulder muscles, was also not affected by the repeated measures within one session $(\mathrm{p}=0.981)$ and the factor "day" had no significant influence on the peak force $(\mathrm{p}=.870)$ demonstrating good repeatability within one session and between two days. The analysis revealed no interactions between the repeated measures, mandibular position and test day for both muscle groups demonstrating that every factor was observed independently from each other. The mean, SD and coefficient of variation for the peak torque of the quadriceps are presented in Table 3. The peak torque of the quadriceps was measured only twice in each mandibular position. As presented in Table 5 the mandibular position had no significant influence on the peak torque of the quadriceps muscle $(\mathrm{p}=0.981)$. The standardized Biodex protocol automatically calculated the mean of the two trials. Consequently, the effect of the repeated measures within one session could not be analysed. The factor "test day" showed no significant effect on the quadriceps peak torque ( $\mathrm{p}=0.585$ ). As showed in Table 3 , a lowered -but not significantvariance on test day 2 for mandibular position was present. Therefore, the possible effect of the fixed factor mandibular position on each test day separately was further analyzed (Table 4). However, the effect of mandibular position analyzed separately on day 1 and day 2 was also not significant ( $\mathrm{p}=.971$ and $\mathrm{p}=.967$ respectively) (Table 5 ).

\section{Discussion}

The rationale of the present study was to assess the influence of three different mandibular positions on muscle force in the limbs and to evaluate the repeatability of the measurements within one session and between two separate days. The results of the present study indicate that in asymptomatic subjects, muscle force in the limbs was not influenced by altering the mandibular position, even if this position was altered with a wax bite. This is in line with the scarce previously reported research who failed to demonstrate improved strength in the shoulder abductor muscles $[2,11,26]$ or grip strength $[8]$ as a result of wearing an oral splint in healthy subjects. In the recent study of Grosdent $e t$ al. [27], the influence of a dental splint on quadriceps muscle force was analysed using comparable Biodex ${ }^{\diamond}$ methodology. In accordance with the results of the present study, these authors also found no significant difference in isometric or isokinetic quadriceps force when the subjects wore a balanced splint. Remarkably, they found a significant immediate decrease in eccentric muscle force of the quadriceps when the occlusion was disturbed by a resin component, possibly explainded by disruption of central modulation mechanisms [27]. In the present study, the wax bite of $2 \mathrm{~mm}$ was taken in the subjects most habitual bite i.e. maximal intercuspidation which was a correct balanced position. However, the small heightening of the vertical dimension of the occlusion may alter the length of the main jaw elevator muscles or the motor unit recruitment of the masseter [13]. Also, the position of the mandibular head in the fossa mandibularis may be influenced symmetrically without creating an imbalance [18]. Nevertheless, the transfer from this study to the clinical situation can be discussed. First, the present study investigated muscle force in an analytical way and no functional related performance tests were included. Secondly, although athletes usually use mouthguards or oral splints when they play sports a wax bite was applied in this study. Regarding the results of the present study it appeared that a small increase in vertical dimension of occlusion in a correctly balanced position has no negative effect on muscular performance. Moreover, good repeatability was demonstrated within one session. This can be explained by the fact that with the aid of dynamometers reliable methods of muscle testing [25] were used with sufficient recovery time between the consecutive measurements. Measurement procedures were carefully standardized which may explain good repeatability over time. In light of the data of the present study, the results of field and

Table 4. Coefficient of variation for the fixed factor quadriceps force for mandibular position only on the two test days.

\begin{tabular}{|c|c|c|c|c|c|}
\hline Day & $\begin{array}{c}\text { mandibular } \\
\text { position }\end{array}$ & $\mathbf{n}$ & Mean & SD & VAR \\
\hline Day 1 & closed & 21 & 176.8 & 57.3 & 32.4 \\
\hline & Open & 21 & 174.5 & 52.4 & 30.0 \\
\hline & Bite & 21 & 178.7 & 56.0 & 31.4 \\
\hline Day 2 & closed & 12 & 173.2 & 45.0 & 26.0 \\
\hline & Open & 12 & 170.7 & 46.4 & 27.2 \\
\hline & Bite & 12 & 168.5 & 42.0 & 24.9 \\
\hline
\end{tabular}

Table 5. $\mathrm{p}$ values for effect of mandibular position and day on quadriceps force and for mandibular position on day 1 and day 2 .

\begin{tabular}{|l|l|l|l|}
\hline Factors & day 1 & day 2 \\
\hline Mandibular position & 0.981 & 0.971 & 0.967 \\
\hline Day & 0.585 & & \\
\hline
\end{tabular}


functional tests reported should be interpreted with caution. It has been reported that jaw clenching could be functionally related to muscles of the upper and lower extremity [22] which can improve performance such as jumping [28]. In patients with TMDs, it has been reported that occlusal splints can have a significant positive effect on psychological variables such as catastrophizing and depression [29]. Moreover, recent fMRI studies reported that the mandibular position possibly can affect cognitive awareness, affective and behavioral dimensions [30]. Although evidence has been provided for neural and biomechanical connections between the trigeminal, neck and shoulder region and other parts of the body, the clinical implications remain unclear. Future research should focus on more dynamic tests [6,31] which might possibly reflect alterations of neuromuscular control systems.

\section{Conclusion}

In conclusion, the results of the present study indicate that in asymptomatic subjects, muscle force in the upper and lower limb was not significantly influenced by different mandibular positions altered by a hard wax bite in maximal occlusion. Good reproducibility of the measurements within one session and between days was demonstrated.

\section{Ethical approvement}

The study was approved by the Ethical Committee of St. Jan Hospital AZ Sint-Jan AV, Bruges, Belgium (BUN: BO49201216115).

\section{Conflicts of interest}

No conflicts of interest declared.

\section{Funding}

This research was carried out without funding.

\section{References}

1. Smith SD (1978) Muscular strength correlated to jaw posture and the temporomandibular joint. N Y State Dent J 44: 278-285. [Crossref]

2. Williams MO, Chaconas SJ, Bader P (1983) The effect of mandibular position on appendage muscle strength. $J$ Prosthet Dent 49: 560-567. [Crossref]

3. Forgione AG, Mehta NR, McQuade CF, Westcott WL (1992) Strenght and bite, Part 2: Testing isometric strength using a MORA set to a functional criterion. Cranio 10: 13-20. [Crossref]

4. Hanke B, Motschall E, Turp J (2007) Association between Orthopedic and Dental Findings: What Level of Evidence is Available? J Orofac Orthop 68: 91-107. [Crossref]

5. Michelotti A, Buonocore G, Manzo P (2011) Dental occlusion and posture: an overview. Prog Orthod 12: 53-58. [Crossref]

6. Perillo L, Femminella B, Farronato D, Baccetti T, Contardo L, et al. (2011) Do malocclusion and Helkimo Index $\geq 5$ correlate with body posture? J Oral Rehabil 38: 242-252. [Crossref]

7. Marini I, Gatto M, Bartolucci M, Borlotti F, Alessandri Bonetti G, et al. (2013) Effects of experimental occlusal interference on body posture: an optoelectronic stereophotogrammetric analysis. J Oral Rehabil 40: 509-518. [Crossref]

8. Yokobori D, Horii A (1993) Effects of wearing splints on muscle strength and equilibrium in athletes. Jpn J Phys Fitness Sports Med 42: 285-291.

9. Bates RE, Atkinson WB (1983) The effects of maxillary MORA's on strength and muscle efficiency tests. J Craniomandibular pract 1: 37-42. [Crossref]

10. Dunn-Lewis C, Luk H, Brett A (2012) The effects of a customized over-the-counter mouth guard on neuromuscular force and power production in trained men and women. J Strength Cond Res 26: 1085-1093. [Crossref]

11. Greenberg MS, Cohen SG, Springer P, Kotwick JE, Vegso JJ (1981) Mandibular position and upper body strenght: a controlled clinical trial. $J$ Am Dent Assoc 103: 576-579. [Crossref]

12. Yates JW, Koen TJ, Semenick DM, Kuftinec MM (1984) Effect of a mandibular orthopedic repositioning appliance on muscular strength. J Am Dent Assoc 108: 331333. [Crossref]

13. Terebesi S, Giannakopoulos NN, Brüstle F, Hellmann D, Türp JC, et al. (2015) Small vertical changes in jaw relation affect motor unit recruitment in the masseter. $J$ Oral Rehabil [Epub ahead of print] [Crossref]

14. McCarroll RS, Naeije M, Kim YK, Hansson TL (1989) Short-term effect of a stabilization splint on the asymmetry of submaximal masticatory muscle activity. $J$ Oral Rehabil 16: 171-176. [Crossref]

15. Perinetti G, Türp JC, Primozic J, Di Lenarda R, Contardo L (2011) Associations between the masticatory system and muscle activity of other body districts. A metaanalysis of surface electromyography studies. J Electromyogr Kinesiol. 21: 877-884. [Crossref]

16. Eriksson PO, Häggman-Henrikson B, Nordh E, Zafar H (2000) Co-ordinated mandibular and head-neck movements during rhythmic jaw activities in man. $J$ Dent Res 79: 1378-1384. [Crossref]

17. Häggmann-Henriksson B, Nordh E, Eriksson PO (2013) Increased sternocleidomastoid, but not trapezius, muscle activity in response to increased chewing load. Eur J Oral Sci 121: 443-449. [Crossref]

18. Lotze M, Lucas C, Domin M, Kordass B (2012) The cerebral representation of temporomandibular joint occlusion and its alternation by occlusal splints. Hum Brain Mapp 33:2984-2993. [Crossref]

19. Treleaven J (2008) Sensorimotor disturbances in neck disorders affecting postura stability, head and eye movement control. Man Ther 13: 2-11. [Crossref]

20. Miyahara T, Hagiya N, Ohyama T, Nakamura Y (1996) Modulation of human soleus H reflex in association with voluntary clenching of the teeth. J Neurophysiolol 76: 20332041. [Crossref]

21. Tuncer M, Tucker KJ, Türker KS (2007) Influence of tooth clench on the soleus H-reflex. Arch Oral Biol 52: 374-376. [Crossref]

22. Sato H, Kawano T, Saito M, Toyoda H, Maeda Y, et al. (2014) Teetch clenching reduces arm abduction force. Exp Brain Res 232: 2281-2291. [Crossref]

23. Schiffman EL, Ohrbach R, Truelove EL, Look J, Anderson G, et al. (2014) Diagnostic criteria for temporomandibular disorders (DC/TMD) for clinical and research applications: recommendations of the international RDC/TMD consortium network and orofacial pain special interest groups. J Oral Fac Pain Headache 28: 6-27.

24. Peolsson A, Hedlund R, Oberg B (2001) Intra- and inter-tester reliability and reference values for hand strength. J Rehabil Med 33: 36-41. [Crossref]

25. Palmer ML, Epler ME (1990) Principles of examination techniques. In: Clinica assessment procedures in physical therapy, Palmer ML and Epler ME (Eds.), Philadelphia: Lippincott Williams \& Wilkins.

26. Schubert MM, Guttu RL, Hunter LH, Hall R, Thomas R (1984) Changes in shoulder and leg strength in athletes wearing mandibular orthopedic repositioning appliances. $J$ Am Dent Assoc 108: 334-7. [Crossref]

27. Grosdent S, O’Thanh R, Domken O, Lamy M, Croisier J-L (2014) Dental occlusion influences knee muscular performances in asymptomatic females. J Strenght Cond Res 28: 492-498. [Crossref]

28. Ebben WP, Flanagan EP, Jensen RL (2008) Jaw clenching results in concurren activation potentiation during the countermovement jump. J Strenght Cond Res 22:1850-1854. [Crossref]

29. Conti YM, Porporatti AL, Staginski-Barbosa J, Bonjardim LR, Conti PC (2015) The additional effects of occlusal splints on the psychological aspects in temporomandibular disorder subjects: a randomized controlled trial. Arch Oral Biol 60: 738-744. [Crossref]

30. Lickteig R, Lotze M, Kordass B (2013) Successful therapy for temporomandibular pain alters anterior insula and cerebellar representations of occlusion. Cephalalgia 33: 12481257. [Crossref]

31. Julià-Sánchez S, Alvarez-Herms J, Gatterer H, Burtscher M, Pages T, Viscor G (2016) The influence of dental occlusion on the body balance in unstable platform increases after high intensity exercise. Neurosci Lett 617: 116-121. [Crossref]

Copyright: (C2016 Isselée H. This is an open-access article distributed under the terms of the Creative Commons Attribution License, which permits unrestricted use, distribution, and reproduction in any medium, provided the original author and source are credited. 